\title{
The Transformation of Society towards Ethical Ideal Surrounding Medical Data and Information
}

\section{Jérôme Béranger ${ }^{1,2 *}$}

${ }^{1}$ Research Associate, UMR ADÉS 7268 - AMU/ EFS, CNRS - Espace Ethique Méditerranéen 27, France

${ }^{2}$ Assistant Director of Scientifique department, Keosys, France

\begin{abstract}
Our current society is a consumption information society where attention is turned towards the epistemological aspect of the data and information as such predominates. In the medium term, this society has become a communication information society focused on information exchange and sharing human. In other words, it must be based on the relationship and not on information from real people. This anthropological vision is essential for converting information into knowledge. A neo-platonic ethics systemic approach highlights a pyramidal representation of knowledge that reflects the evolution of our society healthy from Medicine 1.0 to tend towards Medicine 4.0.
\end{abstract}

Keywords: Society; Transformation; Ethics; Data; Information; Medicine; Modeling

\section{Introduction}

The development of communication systems in our organizations is probably today the primary cause of the acceleration of trade shares and thereby the growth of complexity. It is not always easy to distinguish the concepts of data, information, knowledge, communication and organization that they simply cannot pass each other in articulating more or less harmoniously. A real system is known through the information is circulated inside and outside the system. Under these conditions, a description of epistemological, anthropological and ethical of data flow to a practical wisdom seems essential to develop a deeper understanding of how to evaluate the theoretical and practical implications in the communication within organizations. Tracking data to knowledge to achieve practical wisdom seems essential to develop a deeper understanding of how to evaluate the theoretical and practical implications of the information by New information and communication technologies (NICT) in society.

\section{The development of an information society}

From this, we can establish a pattern that connects the data, information, knowledge and practical wisdom. (Figure 1). This illustration traces the transformation of society based on an ethical ideal framing medical information.

To stay in the spirit of Hippocrates, we must learn to understand and know the human in the digital space. Indeed, Information and communication technology (ICT) must answer the specific needs of caregivers and patients in either a medical dimension, medico-social or human. However, knowledge can be manipulated inappropriately. That is why the creation of a "complex thought" leading to a philosophy of solidarity and non-coercion appears necessary to reach the ultimate stage of a society called ethics information. Complex thinking feeds itself reflexive ethics ${ }^{\mathrm{a}}$ which mission is to provide the practice and the standards, their "legitimacy". The challenge of modernity is to rehabilitate the "relational person" from the exchange of knowledge, cumulative and not exclusive.

For this, we must invent an ethical framework controlled, new close ties that rely on ICT to create a new art of "living together" open

aEthics is always required "to stay awake in his mission legitimation, brought to mobilize its reflexive capacity reference values" [3] plan. This reflection is guided by ethical values that are instances of both normative and critical. Linking knowledge, this approach is centered on the reliance between humans and converts knowledge into "practical wisdom" [1] fundamental in the development of an optimal decision. Practical wisdom whose duty it is to get a wise decision, prudent, given the singular concrete situations. According to [2], "The principle of non-separation is based on solidarity. Thus, the complex thinking leads to an ethic of responsibility (recognition of the autonomous subject) and solidarity (which connects thought). It leads to an ethical understanding that is an ethic of pacification of human relationships. It shows that the greater social complexity, greater are freedoms, greater is the need of solidarity to ensure social cohesion" [3].

\section{The pyramid of knowledge through the prism of ethics modeling}

We note that this evolution of society reflects the three levels of modeling of classical Antiquity that we can convert to contemporary medical events, namely:

- The "Be given" represented by the epistemologically. This is the set of all that constitutes the world where man has a partial or indirect access through the senses. You can designate it as the Medicine 1.0 of the past corresponding to a passive attitude;

- The "sensible world" illustrated by anthropological field centered on human relationships. It represents the world of sensations and the degree being the only source of data that provides information about the real world or "Be given". It can be illustrated as Medicine 2.0 today with a collaborative

*Corresponding author: Jérôme Béranger, Research Associate, UMR ADÉS 7268 - AMU/ EFS, CNRS - Espace Ethique Méditerranéen 27, France; Assistant Director of Scientifique department, Keosys, France, E-mail: jeromeberanger@hotmail.com

Received September 13, 2013; Accepted November 25, 2013; Published November 30, 2013

Citation: Béranger J (2013) The Transformation of Society towards Ethical Idea Surrounding Medical Data and Information. J Gen Pract 1: 136. doi: 10.4172/2329. 9126.1000136

Copyright: (c) 2013 Béranger J, et al. This is an open-access article distributed under the terms of the Creative Commons Attribution License, which permits unrestricted use, distribution, and reproduction in any medium, provided the original author and source are credited. 
approach that everyone can produce its expression on Internet. This is our today's society, involving an exchange between people, especially through forums and social networks;

- The "objective reality" characterized by philosophical thought. It is a fully conceived space by the human mind. It is to construct explanatory models that translate data from the "sensible world". This last phase may represent the Medicine 3.0 of future that has a strong ethical dominance. It is primarily a respect ethics and human values for that the virtual blends into the real. This medicine should be independent and respectful of the doctor-patient relationship to become the guide of our concerns [4]. This situation is illustrated by our triangulation doctor-patient-Information system (IS) where the machine becomes intelligent being able to manage and collect data that make sense. This Medicine 3.0 designed with ethics and intelligence paves the way towards improving the care relationship, a return to semiotics, and the establishment epidemiology of a real-time based on dialogue between doctor and patient.

In addition, from a neo-platonic ethics systemic approach, we can

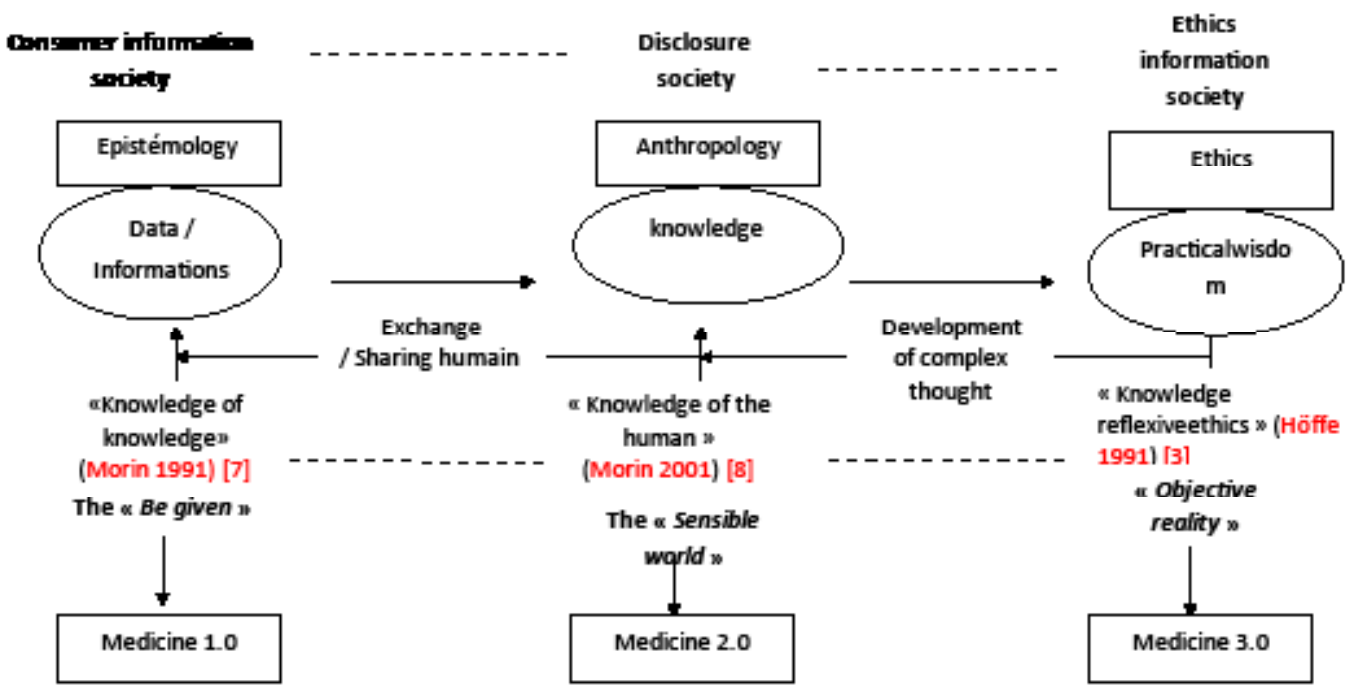

Figure 1: The development of an information society using NICT.

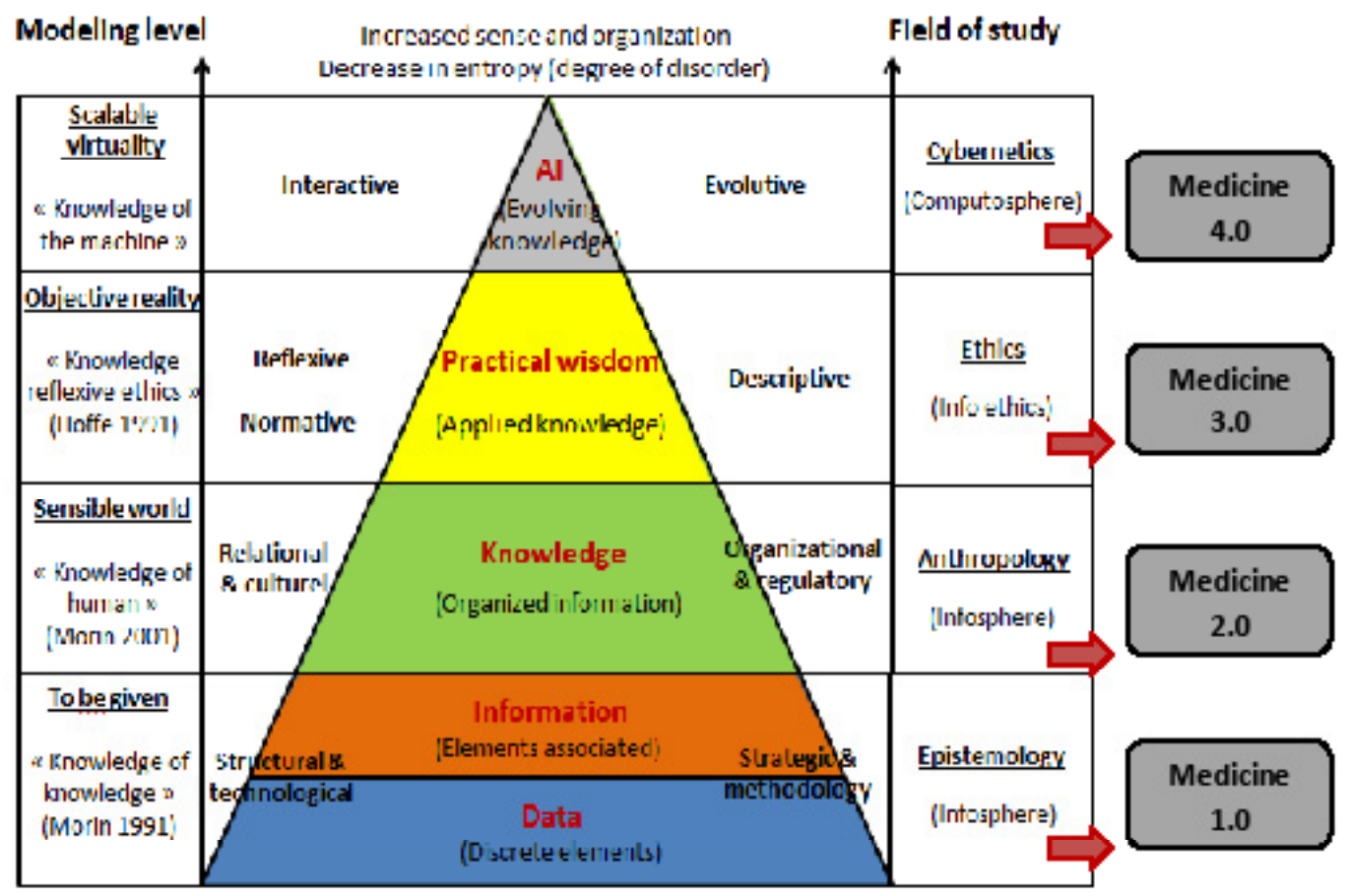

Figure 2: Analysis of the pyramid of knowledge by modeling ethical. 
Citation: Béranger J (2013) The Transformation of Society towards Ethical Ideal Surrounding Medical Data and Information. J Gen Pract 2: 136. doi: 10.4172/2329-9126.1000136

Page 3 of 5

establish a new knowledge representation integrating different levels of modeling based on fields of study. Each field of study is a concept of Medicine (Figure 2).

This pyramidal representation tends towards personalized medicine ethics assisted by NICT which has characteristics of:

- Increase the sense of the care management;

- To decrease the entropy (degree of disorder) of a health organization.

Our model was able to highlight the final stage of processing knowledge, namely the Artificial Intelligence (AI) where machines can self-evolve without the intervention of man. This step corresponds to the level of modeling called "scalable virtuality" where cybernetics ${ }^{b}$ is based on ethics in computosphere ${ }^{c}$ to move towards the Medicine 4.0 (Table 1).

We joined the notion of Internet of things that Joel de Rosnay called 4.0 which is linked to the ability of intelligent machines will talk to each other, regardless of the human will.

This we reference in the world of Isaac Asimov ${ }^{\mathrm{d}}$, author of science fiction, which seeks to provide a rational view of the robot, one of the principles is that the machine does not turn against humans and in fact possession of its own. All the problems that arise come from its creator (Figure 2).

The notion of computosphere is interesting, because if the computer orders and still keeps a link with its designers, the computer calculated without the need to account to its designers, since calculates its own evolution.

The computosphere has three informational characteristics, component IS as expert systems of diagnostic aid: the semantics (the meaning of information), syntax (the flow of information) and lexical (the stock of information).

The semantician Rastier François [5], after recalling the positions of Turing and Grice about offers six "precepts" conditioning dialogue system advanced. Note that they are already being implemented by existing systems:

- Objectivity (Using a knowledge base by system);
- Textuality (Consideration interventions more than a sentence, whether from the system or the user);

- Learning (Integration of information from about the user);

- Questioning (Request clarification from the system);

- Grinding (Suggested corrections to the question, if necessary);

- Explanation (Explanation by the system of a reply given above).

It also suggests that the system should be able to make itself a representation of the user to fit him. For its part, the user tends to adapt to the system, which shows the designer for the pragmatic advantage of simplifying certain aspects of dialogue. Regarding cybernetics, this is all theory on process control and communication and their regulation in the living, in the machinery and the sociological and economic systems. Its main purpose is to study the interactions between "rulers systems" (or control system) and "governed systems" (or operating systems), governed by feedback processes or feedback. Hence the term "cybernetics", which comes from the Greek word "kubernesis" and figuratively means the action of lead, to govern.

The organization is active, self-organizing and is dependent and supportive environment. The organization also responds according to the information. Information is a stable configuration of symbol is both Sign and Meaning. It allows the organization to adapt its behavior at every moment by regulation, to transform, to rebalance to be in harmony with the environmental parameters of the infosphere, the info-ethics and computosphere (Tables 2 and 3).

The information gives rise to a permanent process of adjustment of the organization through the channels (the system adapts by

'Science self-regulating systems, which is not interested in components but their interactions, and that is considered primarily their overall behavior. It's a model of the relationship between the elements system, the study of information and principles interaction.

cAll digitized data are information world and a universe communication, related to the interconnection of computers. It constitutes the support of the informational interconnection between machines.

d"Robots" (original title: I, Robot) is a collection of nine new science fiction written by Isaac Asimov, first published by Gnome Press in 1950 and translated into France in 1967.

\begin{tabular}{|l|c|c|c|c|}
\hline & \multicolumn{2}{|c|}{ Infosphere } & Anthropology & Info-éthics \\
\hline Field of study & Epistemology & Ethics & Computostive reality \\
\hline Modeling level & Be given & Sensible world & Cybernetics \\
\hline Nature of the elements of knowledge & Data / Information & Knowledge & Practical wisdom \\
\hline Type of Medicine & Medicine 1.0 & Medicine 2.0 & Medicine 3.0 \\
\hline Temporality & Past & Present & Near future \\
\hline Nature of the relationship & Man-Machine & Man-Machine & Inter-human \\
\hline Purpose of the management care & Do it well & Do it well & Medicine & To the right \\
\hline
\end{tabular}

Table 1: Descriptive components of environment surrounding the knowledge.

\begin{tabular}{|l|c|c|c|}
\hline & & \multicolumn{2}{|c|}{ Info-éthics } \\
\hline Field of study & Descriptive ethics (Practice) & Normative ethics (Ethics) \\
\hline Ethics & Means & Standards & Reflexive ethics (Question) \\
\hline & Device & Pules & Principe of Beneficence \\
\hline Practical wisdom & Way & Limits & Principe of Non-maleficence \\
\hline & Proceedings & Regulation et adaptation & Principe of Justice \\
\hline
\end{tabular}

Table 2: Environmental parameters info-ethics. 


\begin{tabular}{|l|c|c|}
\hline & \multicolumn{2}{|c|}{ Computosphere } \\
\hline Field of study & Interactive & Scalable \\
\hline & Impartiality & Learning \\
\hline Cybernetic : & Textuality & Questioning \\
\hline Artificial Intelligence (Al) & Explanation & Rectification \\
\hline
\end{tabular}

Table 3: Environmental parameters computosphere.

\begin{tabular}{|c|c|c|c|c|}
\hline $\begin{array}{l}\text { Level of } \\
\text { knowledge }\end{array}$ & Nature & Content & Function & Filter \\
\hline & & Numbers & Categorize & \\
\hline Data & & Codes & Calculate & $\begin{array}{l}\text { Visualization } \\
\text { and perception }\end{array}$ \\
\hline \multirow[t]{5}{*}{ Discreteelements } & Epistémology & Tables & Collect & (What's this ?) \\
\hline & & Databases & Measure & \\
\hline & & & Collect & \\
\hline & & Sentences & Contextualize & \\
\hline & & Paragraphs & Compare & \\
\hline Information & & Equations & Order & $\begin{array}{l}\text { Design and } \\
\text { implementation }\end{array}$ \\
\hline \multirow[t]{5}{*}{ Items related } & Epistémology & Concepts & Converse & (How ?) \\
\hline & & Ideas & Filter & \\
\hline & & Questions & Framing & \\
\hline & & $\begin{array}{l}\text { Simple } \\
\text { stories }\end{array}$ & Prioritize & \\
\hline & & Chapters & Structuring & \\
\hline Knowledge & & Théories & Understand & $\begin{array}{l}\text { Mapping and } \\
\text { use }\end{array}$ \\
\hline \multirow[t]{6}{*}{$\begin{array}{l}\text { Organized } \\
\text { information }\end{array}$} & Anthropology & Axioms & Read & (Why ?) \\
\hline & & $\begin{array}{l}\text { Conceptual } \\
\text { frame works }\end{array}$ & Evaluate & \\
\hline & & $\begin{array}{l}\text { Complex } \\
\text { stories }\end{array}$ & Démolish & \\
\hline & & Books & Protect & \\
\hline & & Paradigms & Emboly & \\
\hline & & Systems & Adapter & $\begin{array}{l}\text { Effectuation, } \\
\text { control et } \\
\text { legitimation }\end{array}$ \\
\hline Practical wisdom & & $\begin{array}{l}\text { Religion / } \\
\text { Beliefs }\end{array}$ & Synthesize & $\begin{array}{l}\text { (What is the } \\
\text { best?) }\end{array}$ \\
\hline \multirow[t]{5}{*}{$\begin{array}{l}\text { Applied } \\
\text { knowledge }\end{array}$} & Ethics & Philosophies & Apply & \\
\hline & & Traditions & & \\
\hline & & Principles & & \\
\hline & & Truths & & \\
\hline & & $\begin{array}{l}\text { Schools of } \\
\text { throught }\end{array}$ & & \\
\hline
\end{tabular}

Table 4: Structure of the pyramid of knowledge.

accommodation) and codes (the system adapts by assimilation) communication over a project. To represent the organization, it offers a model consisting a decision system, an information system and an operating system.

\section{Filters and structure of the pyramid of knowledge}

The pyramid of knowledge involves control filters for each field of study (Table 4).

- Display filter / of perception, and design / implementation filter in epistemology (Medicine 1.0);

- Filter mapping and use in anthropology (Medicine 2.0);

- Filter effectuation, regulatory and legitimating in ethics (Medicine 3.0);

- Filter evolution in cybernetic (Medicine 4.0).
It is from this perspective on the evolution of our information society; we have developed our model of ethical analysis applied to New information and communication technologies (NICT). Note that the idea of using mathematics to describe the "sensible world" seems to come from Pythagore and the Pythagoreans [6].

In summary, complex thinking loop attachment epistemology and anthropology. Epistemology can design anthropology, which is a prerequisite to a philosophical thought, which fits into a loop where each step is necessary to achieve an ethic.

Finally, cybernetics will rely on the info-ethics to develop Artificial Intelligence, that is to say, the evolutionary knowledge of expert systems to aid diagnosis.

In other words, these four macroscopic stages of society can be illustrated by a microscopic approach of an information system resulting in its design, implementation, use and development.

\section{Conclusion}

Today the interaction of society with the new information technologies is an unstable system view precarious. It increases the range of choices, often contradictory. We must observe the changes underway as the anxieties aroused by the destructive power of technology awakening our ethical requirements. This combination of "virtual" and "real" has made the balance of exchange and sharing processes of sensitive information, complex and unstable. Now, the individual must think, sort and relocate every information in a rational scale in order to be able to assume your choices and decisions. The information takes an important place in these new powers and even becomes a requirement. The development of medical information consumerism associated with NICT marks an important development in human relationships by acting in depth social relationships, men's beliefs and the nature of knowledge. Communication is to assess all interactions implemented in society.

In our opinion, the "technological" modernization of the use of medical information must be accompanied by modernization "ethical" designing an information system with a human face.

This necessarily involves an ethical centered on the quest for meaning technical tool, and whose main objective is to take into account the human issues in order to control the deviations and risks that may occur. That is why it is always very difficult for a society to be in the middle position. Perhaps the ethical considerations will then its contribution to addressing the world of data, information, knowledge and communication as a new environment: the ethics infosphere. In addition, if this model is applied to the economy, we see that we are at the stage 3.0 as the individual, society and the machine exchange intelligent data.

Therefore, markets, and certain economic and financial machinery already operate in $4.0^{\mathrm{e}}$ which man has become the toy. This should alert us to the fact that if the Medicine 3.0 is not centered on an ethic of inter-human relationships that surround NICT in health, then the man will be dependent on a Medicine 4.0 where our lives will be under the influence of rational medical decision of machines. Under these conditions, the era of consumer health information must be replaced by that of communication of information where sharing, exchange and

${ }^{\text {e}}$ The trajectory of the oil depends on the oil price, which is fixed in part by speculation that makes computer programs on the price of oil. 
Citation: Béranger J (2013) The Transformation of Society towards Ethical Ideal Surrounding Medical Data and Information. J Gen Pract 2: 136. doi: 10.4172/2329-9126.1000136

Page 5 of 5

knowledge are at the crossroads of human relations. We can now ask some questions.

Which sectors use the "sharing of medical information" and associated practices? Are they new? What types of knowledge and medical information is talking about? Can they share and how? How to access the communication of digital medical information to the entire population, including illiterate people?

\section{References}

1. Ricoeur P (1991) The Just. Paris, Seuil, 72-101.
2. Morin E (2004) Method 6 : Ethics. Paris, Seuil.

3. Höffe O (1991) The political justice: a foundation for critical Philosophy and of law and State. In German J Chr Merle, Paris 38-40.

4. Etienne L (2012) Ethics in the use of digital health. Day organized by the National Council of the College of Physicians.

5. Rastier F (2001) Semantic and cognitive research. (2ndedn), Paris

6. Dixaut M, Brancacci A (2003) Platon, Pythagore and the Pythagoreans. History of Philosophy, Paris, Vrin, p.20.

7. Morin E (1991) Method 4: Ideas. Paris, Seuil.

8. Morin E (2001) Method 5: The Humanity oh humanity. Paris, Seuil. 